\title{
Dust Removal Technology Demonstration for a Lunar Habitat
}

\author{
$\underline{\text { C.I. Calle }}^{1}$, A. Chen ${ }^{2}$, C.D. Immer ${ }^{3}$, M. Csonka ${ }^{3}$, M.D. Hogue ${ }^{1}$, S.J. Snyder ${ }^{3}$, M. Rogriquez ${ }^{4}$, and \\ D.V. Margiotta ${ }^{4}$ \\ ${ }^{1}$ Electrostatics and Surface Physics Laboratory, NASA, Kennedy Space Center, FL 32899. \\ ${ }^{2}$ Department of Physics, Oklahoma Baptist University, Shawnee, OK, 74804 \\ ${ }^{3}$ ASRC Aerospace, Kennedy Space Center, FL 32899. \\ ${ }^{4}$ NASA Goddard Space Flight Center, Greenbelt, MD
}

We have developed an Electrodynamic Dust Shield (EDS), an active dust mitigation technology with applications to solar panels, thermal radiators, optical systems, visors, seals and connectors. This active technology is capable of removing dust and granular material with diameters as large as several hundred microns. In this paper, we report on the development of three types of EDS systems for NASA's Habitat Demonstration Unit (HDU). A transparent EDS $20 \mathrm{~cm}$ in diameter with indium tin oxide electrodes on a $0.1 \mathrm{~mm}$-thick polyethylene terephtalate (PET) film was constructed for viewport dust protection. Two opaque EDS systems with copper electrodes on 0.1 mm-thick Kapton were also built to demonstrate dust removal on the doors of the HDU. A lotus coating that minimizes dust adhesion was added to one of the last two EDS systems to demonstrate the effectiveness of the combined systems.

\section{Introduction}

NASA is developing a large scale Pressurized Excursion Module (PEM) as part of its Habitat Demonstration Unit (HDU) project. The HDU project seeks to investigate and demonstrate concepts, technologies, and architectures for lunar exploration. The PEM, based on NASA's Constellation Architecture scenario 12.1 concept, is the first habitation prototype to be used for these demonstrations (Figure 1). The HDU project will be conducting its first round of analog tests at NASA's Desert Research and Technology Study (D-RaTS) yearly event in the Arizona desert.

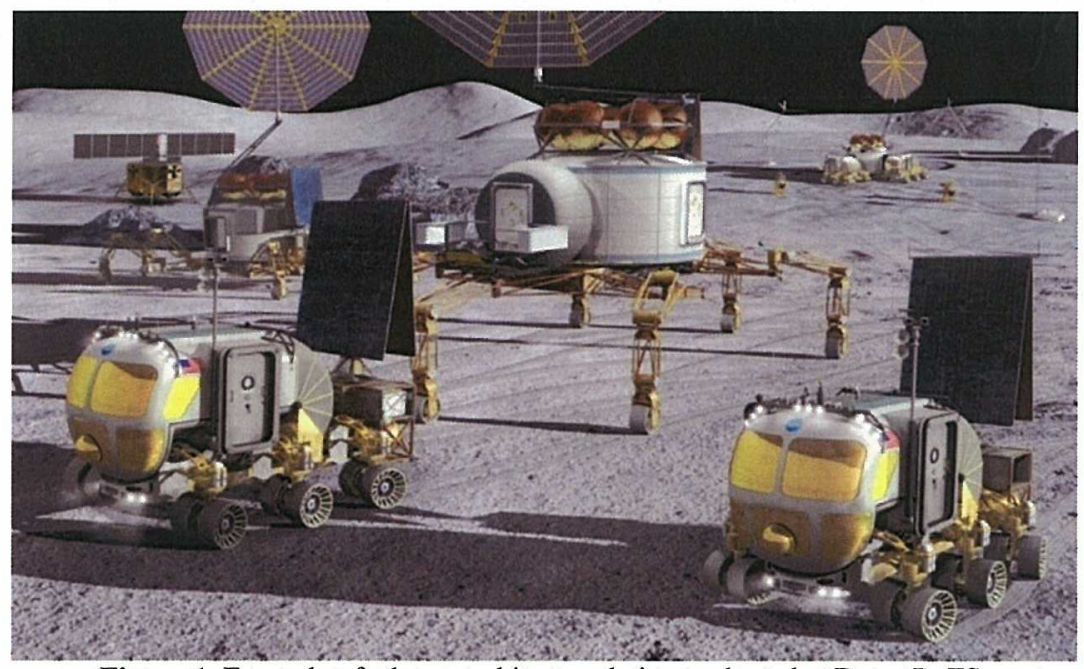

Figure 1. Example of a lunar architecture being evaluated at DesertRaTS.

The PEM has four doors with docking demonstration capabilities. Each door contains a 21-cm diameter viewport. During docking activities with the Lunar Electric Rover (LER), which contains a similar door, the two doors open inward. Any dust accumulating on the surface of these doors must be removed prior to docking. Figure 1 shows an example of a lunar architecture that is being evaluated at D-RaTS.

The Electrodynamic Dust Shield (EDS) technology being developed during the past several years at NASA Kennedy Space Center as an active dust removal system is being used to demonstrate dust removal from the PEM door. A transparent EDS system has also been installed on one of the viewports to maintain it dust-free during the Desert RaTS activities.

The Lotus coating technology is currently being developed at NASA Goddard Space Flight Center as a passive dust mitigating coating. This coating has been used in combination with the active EDS technology to further enhance dust removal from the PEM door.

In this paper, we describe the development of the different EDS systems installed on the PEM and the demonstration tests planned for D-RaTS. We also describe scale up plans for future HDU demonstrations.

\section{The Electrodynamic Dust Shield Technology}

The EDS consists of a series of parallel electrodes connected to a multi-phase AC source that generates a traveling 
electrodynamic wave. This traveling wave allows controlled particle transport which can direct particles to a specific location. The EDS has been described in detail elsewhere. ${ }^{1,2}$ The schematic diagram of Fig. 2 shows the three-phase electrode layout and the signal input of the EDS basic configuration. To illustrate the non uniformity of the electric field generated by this configuration, only one field line between consecutive electrodes is shown. The strength of the field varies proportionally to the potential difference between electrodes, which is dictated by the phase shift. Charged particles move in response to this non uniform field, as shown in Fig. 2.

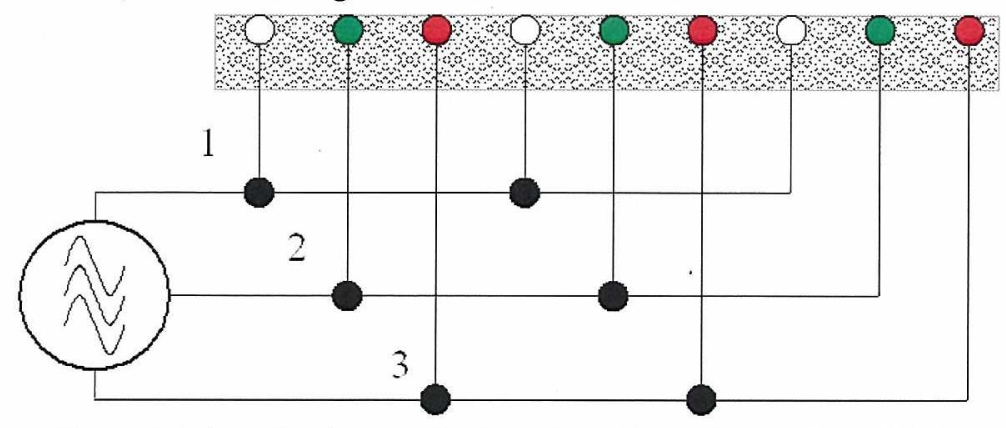

Figure 2. Schematic diagram of a three-phase Electrodynamic Dust Shield.

EDS systems have been developed in our NASA laboratory for dust mitigation of solar panels, optical systems, viewports, thermal radiators, and spacesuits for lunar and Martian exploration missions. ${ }^{3-6}$ The EDS systems developed for these demonstrations have ranged in size from $2.5-\mathrm{cm}$ diameter discs for thermal radiators to $10 \mathrm{~cm}^{2}$ for spacesuit fabrics.

\section{Lotus Coating Technology}

The Lotus dust mitigation coating is a passive technology that is being developed and tested at NASA Goddard Space Flight Center (GSFC) as a countermeasure for addressing dust accumulation issues for long-duration human space exploration. This coating sheds dust particles utilizing anti-contamination and self-cleaning properties that minimize dust accumulation on spacecraft surfaces. Shedding of dust particles is accomplished by reducing the surface energy and the amount of surface available for attachment. The Lotus coating is designed to preserve optimal long-term performance of critical spacecraft surfaces and systems, while minimizing and/or eliminating dust accumulation. The Lotus coating can be applied to commonly used space craft substrates such as metal, glass, thermal control coatings and polymer substrates.

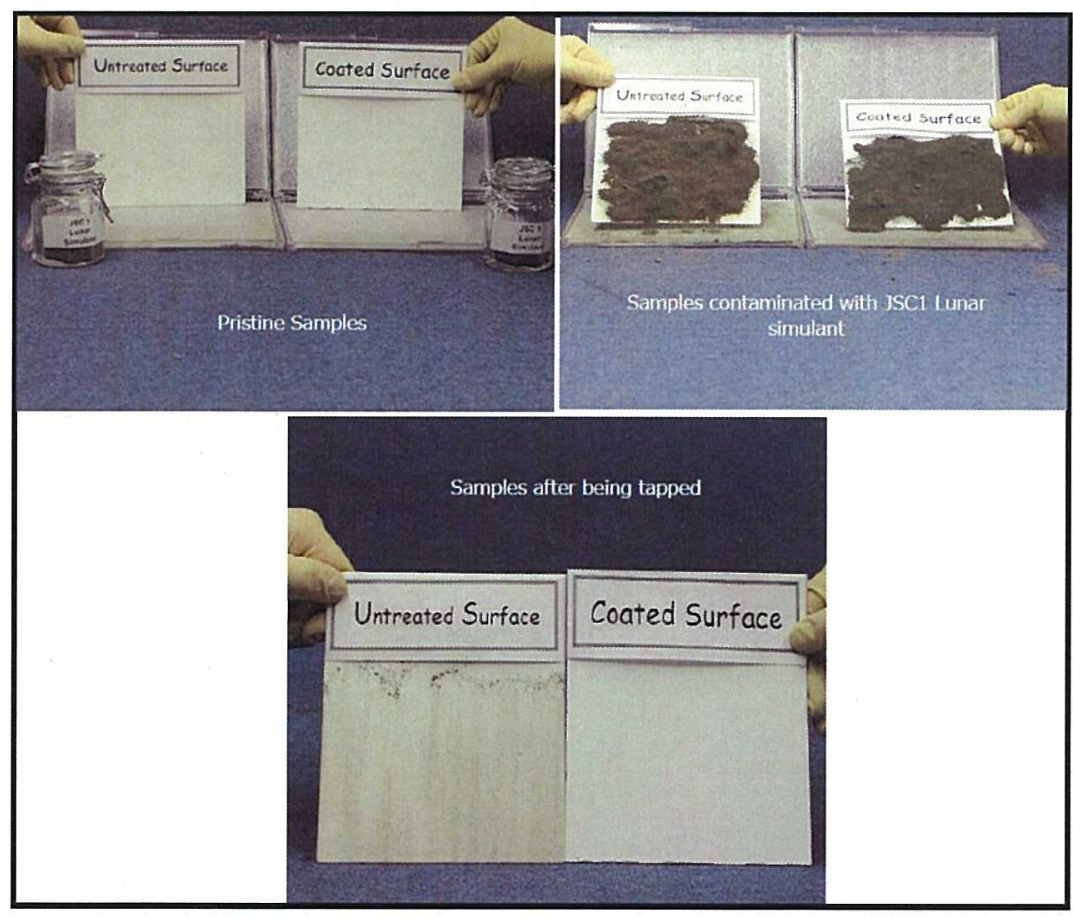

Figure 3. Anti-Contamination/self-cleaning properties assessment of untreated and treated Lotus coated radiator samples

The Lotus coating technology is named after the natural self-cleaning phenomenon that the lotus leaf exhibits. The lotus leaf has the ability to repel water and dirt due to its unique surface architecture. This architecture creates a super-hydrophobic 
boundary which aids in reducing the surface energy and area that is required for particle adhesion. The simulated "Lotus" coating is achieved in practice by creating a nano-texture on the surface of a material followed by the application of a thin hydrophobic layer. Simultaneously, the two layers work together to give the coating super-hydrophobic properties. ${ }^{7}$
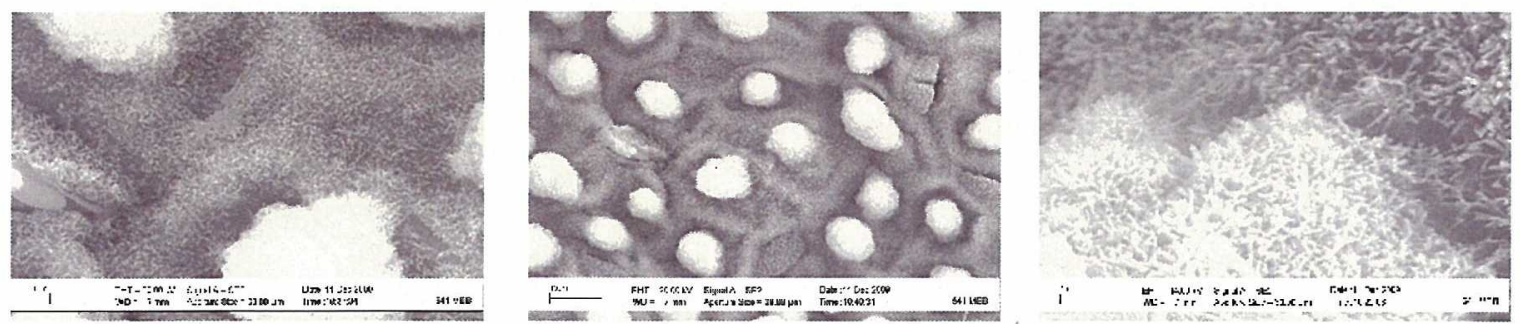

Figure 4. Scanning electron microscope images of lotus leaf's nano structures

\section{Electrostatic Dust Shield Designs for the Pressurized Excursion Module}

For the PEM demonstration, the EDS had to be scaled up to larger sizes. A transparent $20 \mathrm{~cm}$ diameter EDS with indium-tin oxide (ITO) electrodes on a polyethylene terephthalate (PET) film was developed and tested to protect the PEM viewport. Three $20 \mathrm{~cm} \times 25 \mathrm{~cm}$ EDS with copper electrodes on Kapton ${ }^{\mathrm{TM}}$ film $0.1 \mathrm{~mm}$ thick were also manufactured and tested. Two of these dust shields were coated with the Lotus coating. One of the two Lotus-EDS panels was painted with A276 white thermal paint. This thermal paint has been used in space and is a useful coating for short term missions. ${ }^{8}$ A fourth Kapton ${ }^{\mathrm{TM}}$ panel was installed as a control. This panel was divided into four sections: plain Kapton ${ }^{\mathrm{TM}}$, Lotus coating, Lotus coating on A276 paint, and A276 paint. Figure 5 (a) shows four panels installed on one of the PEM doors and the transparent EDS covering the viewport. Figure 5 (b) shows the finished PEM with the Lunar Electric Rover mated.
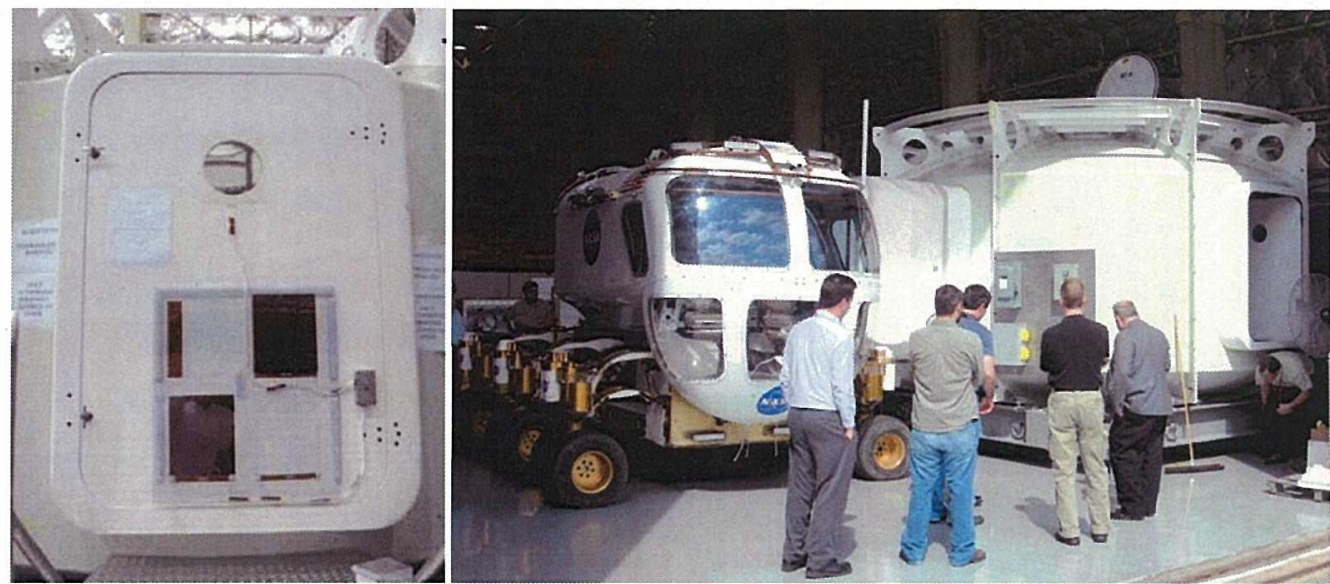

Figure 5 (a). One of the PEM doors with the EDS systems installed. (b) The Lunar Electric Rover mated to the PEM.

The EDS systems developed for the PEM demonstration use a two-phase electrode design. The figure depicts the electrode layout for one of the EDS systems after installation on the PEM door. The two-phase electrode configuration consists of two sets of parallel copper electrodes interlaced in a comb configuration. Each set is connected to one of the signal inputs which have a $180^{\circ}$ phase shift.

The four EDS systems were connected in parallel. A power supply, installed under the PEM floor, provided power to the EDS systems (Fig. 6). The operation of the EDS systems was controlled with a LabView program running on a small computer attached to the power supply.
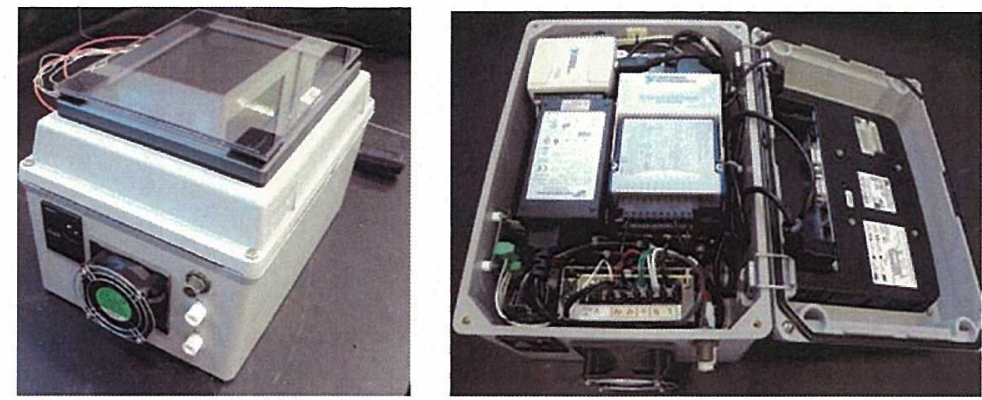

Figure 6. Power supply and computer with LabView ${ }^{\mathrm{TM}}$ control program. The unit has been installed under the floor of the PEM. 


\section{Laboratory and Post Installation Tests}

Laboratory tests were conducted with a $10 \mathrm{~Hz}$ two-phase square wave input signal in a glove box at room temperature and standard pressure. We used JSC-1A lunar simulant grains in the size range of 50 to 100 micrometers. This simulant, produced from a volcanic tuff near Flagstaff, Arizona, has a mineral composition similar to certain soils found at the Apollo 14 landing site. ${ }^{9,10}$ The size range was selected because it lies outside the respirable range and was therefore considered safe to use in repeated testing.

The simulant dust was sprinkled over the EDS units by hand using a 1-cm wide nylon brush inside a portable vent hood. The EDS units were first placed horizontally, as shown in Fig. 7. The two-phase signal was activated, supplying about 100 $\mathrm{mW}$ of power to the EDS for 60 seconds. Fig. 7 shows the 20 -cm diameter transparent EDS with JSC-1A dust sprinkled on it (left side of the figure). The photograph on the right of Fig. 7 shows the EDS after activation, with dust swept outside the perimeter of the electrode layout. Additional tests were also performed with the EDS units in a vertical position.

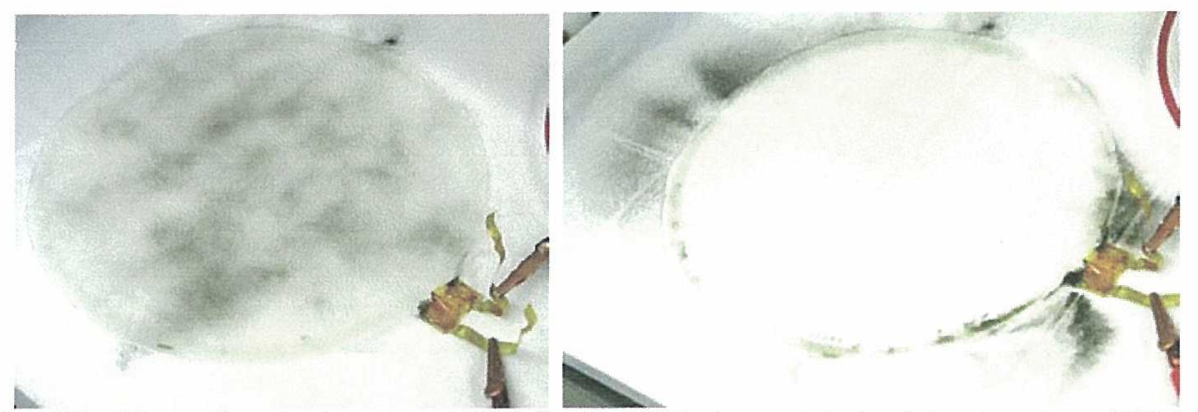

Figure 7. Photographs of the $20-\mathrm{cm}$ diameter transparent EDS for the PEM viewport during laboratory tests. JSC-1A stimulant dust was deposited in a relatively uniform fashion, as shown on the left. The photograph on the right shows the EDS after activation. Dust has been removed to the region outside the electrode grid. These tests were performed with the EDS sitting horizontally in a glove box.
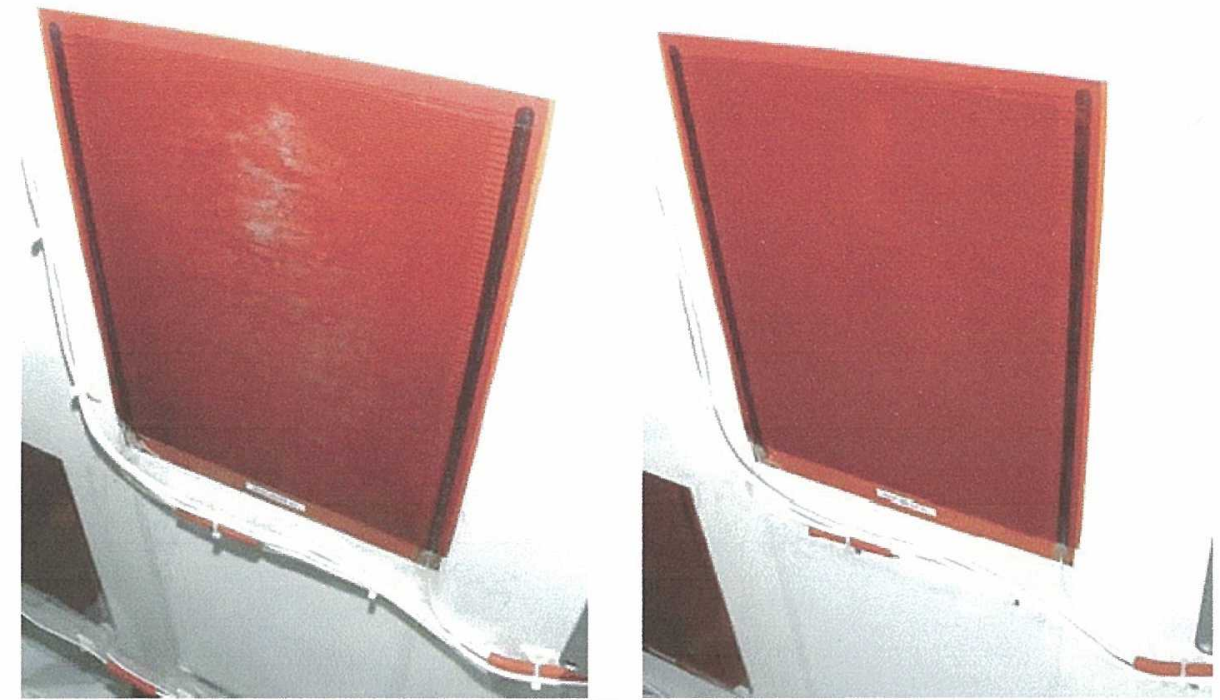

Figure 8. Post installation tests of the $20 \mathrm{~cm} \times 25 \mathrm{~cm}$ EDS. JSC-1A simulant dust was slung at the EDS with a nylon brush.

Tests were performed on the final EDS units with and without the Lotus coating after installation on the PEM at the Johnson Space Center. Fig. 8 shows the result of these tests on the EDS units without the Louts coating. JSC-1 A simulant dust in the 50 to 100 micrometer range was slung at the EDS units with a nylon brush. Triboelectric charging of the dust in contact with the brush bristles allowed a fraction of the dust to adhere to the EDS units, as shown on the photograph on the left of Fig. 8. The photograph on the right shows the EDS after activation. The EDS units with the Lotus coating application enhanced the elimination of the dust from the contaminated surface.

Performance of the EDS systems installed on the PEM will be measured during the 2010 DesertRATS event using a spectrometer, a digital camera, and a portable microscope. Images and data from these instruments will provide dust removal efficiency information. We will report on those measurements in the future.

\section{Acknowledgments}

This project was supported by a Kennedy Space Center Director's Discretionary Fund. We would like to thank Tracy Gill of NASA Kennedy Space Center for his support of this project. 


\section{References}

'Calle, C.I., C.R. Buhler, J.L. McFall, and S.J. Snyder, "Particle removal by electrostatic and dielectrophoretic forces for dust control during lunar exploration missions," Journal of Electrostatics 67 (2009) 89-92.

${ }^{2}$ Calle, C.I., M.K. Mazumder, C.D. Immer, C.R. Buhler, J.S. Clements, P. Lundeen, A. Chen, and J.G. Mantovani, "Controlled particle removal from surfaces by electrodynamic methods for terrestrial, lunar, and Martian environmental conditions," Journal of Physics, 142, $012073(2008)$

${ }^{3}$ Calle, C.I., A. Chen, J. Meyer, B. Linell, C.R. Buhler, S. Clements, and M.K. Mazumder, 'Numerical modeling of an electrostatic dust shield for the Martian and lunar environments," Earth and Space 2006, Houston (2006)

${ }^{4} I m m e r$, C. J. Starnes, M. Michalenko, C.I. Calle, and M.K. Mazumder, "Electrostatic screen for transport of Martian and lunar regolith," Lunar and Planetary Science XXXVII, 2265 (2006)

${ }^{5}$ Mazumder, M., M. Zahn, R. Sharma, J. Zhang, C.I. Calle, C. Immer, and N. Mardesich, "Development of self-cleaning dust shields using low-power electrodynamic fields for solar panels on Mars," Proceedings of the 2006 ESA/IEJ/IEEE-IAS/SFE Joint Conference on Electrostatics, Laplacian Press, Morgan Hill, CA (2006)

${ }^{6}$ Calle, C.I., C.R. Buhler, M.D. Hogue, M.R. Johansen, N.J. Van Suetendael, A. Chen, S.O. Case, S.J. Snyder, J.S. Clements, J.A. Moebus, J.B. Miller, N.D. Cox, and S.A. Irwin, "Development of a dust mitigation technology for thermal radiators for lunar exploration," Proceedings of the IEEE Aerospace Conference, Big Sky, Montana (2010)

${ }^{7}$ Margiotta, D.V., W.C. Peters, S.A. Straka, M. Rodriguez, K.R. McKittrick, and C.B. Jones, "The Lotus coating for space exploration - A dust mitigation tool," Proceedings for the 2010 SPIE Conference San Diego, California(2010)

${ }^{8}$ Golden, J.L, "Results of examination of the A276 white and Z306 black thermal control paint disks flown on LDEF," LDEF-69 Months in space: First port-retrieval symposium, NASA CP-3134, June 1991.

${ }^{9}$ McKay, D.S., J.L. Carter, W.W. Boles, C.C. Allen, and J.H. Alton, "JSC-1: A new lunar stimulant," $24^{\text {th }}$ Lunar and Planetary Science Conference, p. 963.

${ }^{10}$ Wallace, W.T., L.A. Taylor, Y. Liu, B.L. Cooper, D.S. McKay, B. Chen, and A.S. Jeevarajan, "Lunar dust and lunar simulant activation and monitoring," Meteoritics and Planetary Science 44, 9561-970 (2009) 